\title{
A Novel in Situ FPAR Measurement Method for Low Canopy Vegetation Based on a Digital Camera and Reference Panel
}

\section{Liangyun Liu *, Dailiang Peng, Yong Hu and Quanjun Jiao}

Key Laboratory of Digital Earth Science, Center for Earth Observation and Digital Earth, Chinese Academy of Sciences, Beijing 100094, China; E-Mails: dlpeng@ceode.ac.cn (D.P.); huyong@ceode.ac.cn (Y.H.); qjjiao@ceode.ac.cn (Q.J.)

* Author to whom correspondence should be addressed; E-Mail: lyliu@ceode.ac.cn; Tel.: +86-10-8217-8163; Fax: +86-10-8217-8163.

Received: 20 November 2012; in revised form: 6 January 2013 / Accepted: 6 January 2013 / Published: 15 January 2013

\begin{abstract}
The fraction of absorbed photosynthetically active radiation (FPAR) is a key parameter in describing the exchange of fluxes of energy, mass and momentum between the surface and atmosphere. In this study, we present a method to measure FPAR using a digital camera and a reference panel. A digital camera was used to capture color images of low canopy vegetation, which contained a reference panel in one corner of the field of view (FOV). The digital image was classified into photosynthetically active vegetation, ground litter, sunlit soil, shadow soil, and the reference panel. The relative intensity of the incident photosynthetically active radiation (PAR), scene-reflected PAR, exposed background absorbed PAR and the green vegetation-covered ground absorbed PAR were derived from the digital camera image, and then FPAR was calculated. This method was validated on eight plots with four vegetation species using FPAR measured by a SunScan instrument. A linear correlation with a coefficient of determination $\left(\mathrm{R}^{2}\right)$ of 0.942 and mean absolute error (MAE) of 0.031 was observed between FPAR values derived from the digital camera and measurement using the SunScan instrument. The result suggests that the present method can be used to accurately measure the FPAR of low canopy vegetation.
\end{abstract}

Keywords: FPAR; digital camera; classification; reference panel 


\section{Introduction}

The fraction of absorbed photosynthetically active radiation (FPAR) characterizes the function of vegetation canopy and its energy absorption capacity. FPAR is a key parameter in describing the exchange of fluxes of energy, mass and momentum between the surface and atmosphere in global models of climate, hydrology, biogeochemistry, and ecology [1]. With the significant increase in global satellite-derived biophysical datasets in recent years, FPAR has been identified as an essential climate variable by the Global Climate Observing System and one of several key terrestrial products [1,2]. Therefore, validation of the available FPAR products by field measurements has received more attention in recent years [3]. The challenge is how to make accurate field-based FPAR measurements.

FPAR is generally defined as the fraction of photosynthetically active radiation (PAR) absorbed by vegetation in the 400-700 $\mathrm{nm}$ spectral range. Many radiometers can be used to measure PAR, such as the SunScan canopy analysis system. SunScan has an array of 64 PAR sensors embedded in a 1-m long probe, with a size of $130 \mathrm{~cm}(\mathrm{l}) \times 10 \mathrm{~cm} \mathrm{(w)} \times 13 \mathrm{~cm}(\mathrm{~h})$. The radiometer can be used to measure FPAR by comparing the incident and reflected PAR above and below the canopy [4]. However, for very-low canopy vegetation, such as the grassland with a height less than $15 \mathrm{~cm}$, which is the case in many arid and semi-arid regions in the world, it is impossible to put the SunScan probe below the canopy to measure canopy-transmitted and background-reflected PAR to calculate FPAR.

The development of charged coupled device (CCD) cameras has opened up the possibility of new techniques employing two-dimensional imaging. Digital cameras have adequate bandwidth covering the visible range (400-700 nm) [5], which is consistent with the bandwidth of the definition of PAR. Digital cameras have been used to estimate vegetation coverage [6-8], and statistical relations between digital image parameters and canopy leaf area index (LAI) or FPAR have also been applied extensively [9]. A popular method used to measure FPAR is digital hemispherical (fisheye) photography (DHP), which is a technique for characterizing plant canopies (especially for the forest) using photographs taken looking upward through an extreme wide-angle lens [10]. Still, it is also impossible to take photographs beneath the canopy of low grassland.

There is still no effective method to measure canopy FPAR for very-low canopy vegetation. In this paper, we present a novel method to measure FPAR using a digital camera and reference panel, and evaluate the method by traditional radiation transmittance measurements in eight independent plots with the low canopy of approximately $30-50 \mathrm{~cm}$.

\section{Method}

Canopy FPAR is traditionally measured with a radiometer. According to Jenkins et al. [4], the absorbed photosynthetically active radiation (APAR) can be calculated by the following expression:

$$
A P A R=P A R_{i}-P A R_{r}-P A R_{g}
$$

where $\mathrm{PAR}_{\mathrm{i}}$ and $\mathrm{PAR}_{\mathrm{r}}$ are the incident and scene-reflected (including contributions from all exposed scene components) PAR (400-700 nm), PAR $\mathrm{g}$ is the background absorbed PAR (including the exposed soil, green vegetation-covered soil, and ground litter). FPAR is given by:

$$
F P A R=A P A R / P A R_{i}
$$


However, for very-low canopy vegetation $(<15 \mathrm{~cm})$, as shown in Figure 1(a,b), respectively, it is impossible to measure canopy FPAR with a general radiometer (e.g., SunScan) or DHP method.

Figure 1. Two very-low canopy vegetation sites, (a) alpine steppe of the Tibetan Plateau and (b) temperate grassland in Inner Mongolia, China.

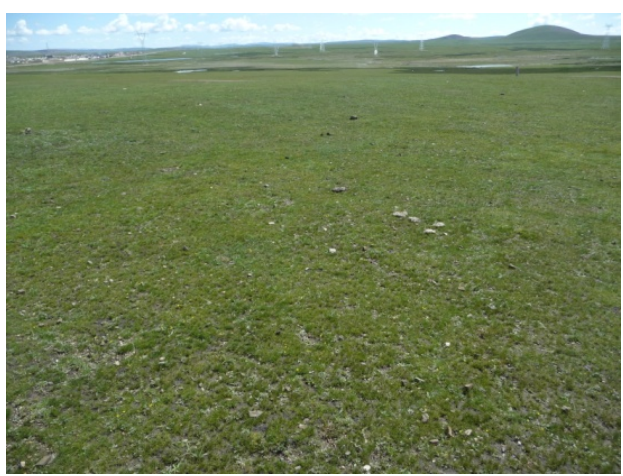

(a)

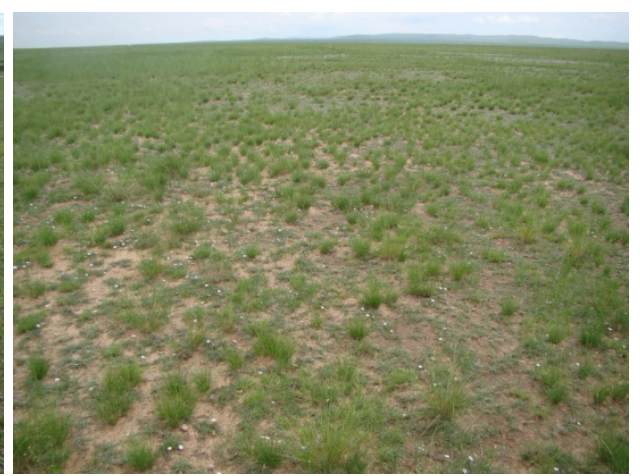

(b)

Based on the above approach, we present a new method to measure FPAR by integrating a digital camera and a Lambertian panel. To demonstrate and test the approach, low canopies suitable for SunScan were selected, and their photos were taken by the digital camera vertically, with a low reflectance panel fixed at one corner of field of view (FOV), and the four components for APAR as shown in Equation (1) are derived from the digital photo. The flowchart to derive the green vegetation FPAR from the digital photo is illustrated in Figure 2.

Figure 2. Diagram of green vegetation FPAR estimation based on a digital camera photo. The photo was taken vertically at a height of $1.5 \mathrm{~m}$ in the digital camera's raw file format, and the area was about $2 \mathrm{~m}^{2}$.

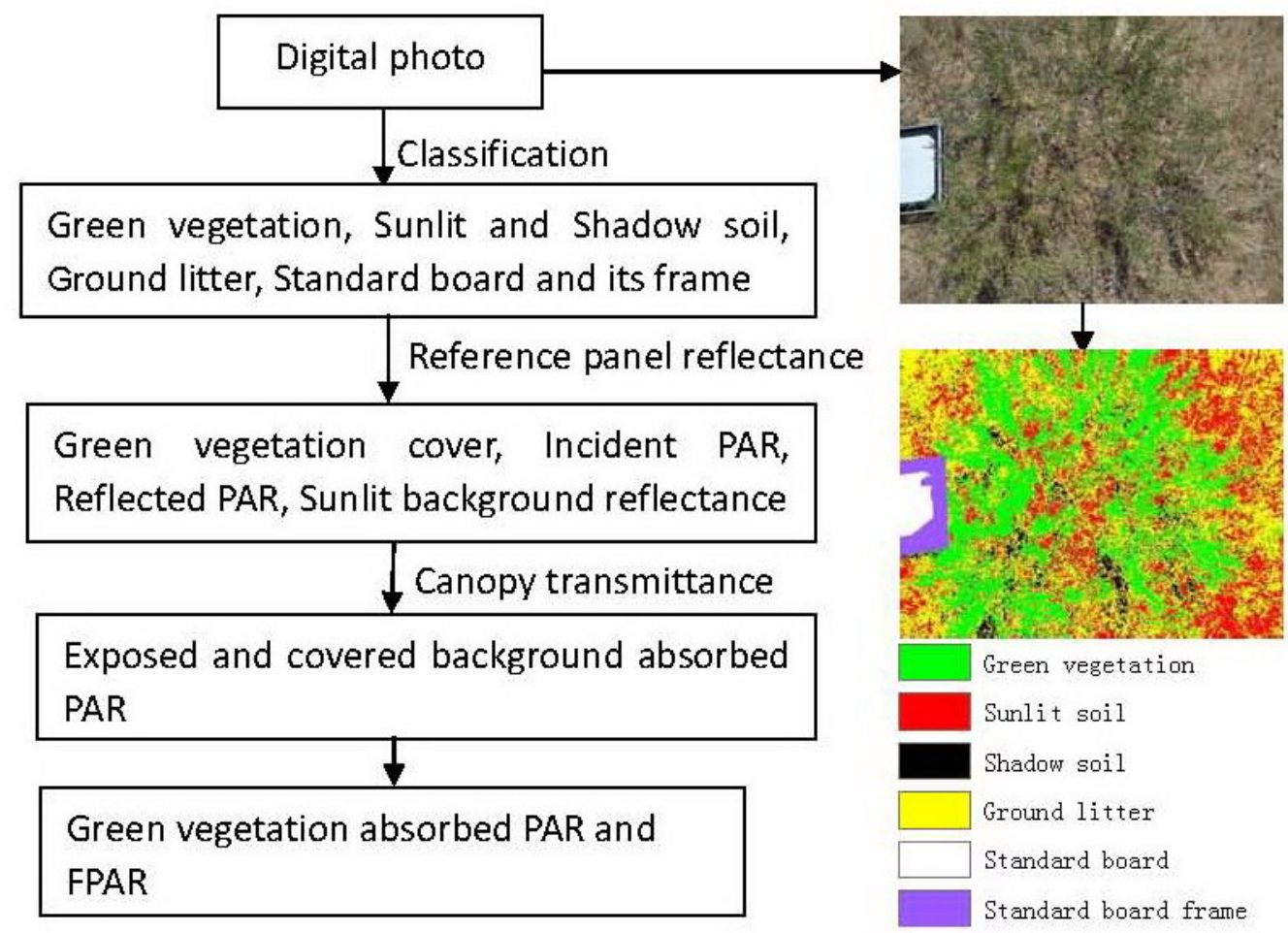




\subsection{Scene Classification}

Based on the visual interpretation, we selected the training pixels, and then the digital photo was classified into five classes by supervised classification method in ENVI software, including green vegetation, sunlit and shadow soil, ground litter, standard board and its frame, and then the pixel count and the average digital number (DN) for each class were calculated. From the classification result, the fractional cover of green vegetation $\left(f_{c}\right)$, was defined as the ratio of green vegetation to total area as derived by pixel counts.

\subsection{Calculation of Incident PAR and Scene-Reflected PAR}

The relative intensity values of $\mathrm{PAR}_{\mathrm{i}}$ and $\mathrm{PAR}_{\mathrm{r}}$ were directly derived from the $\mathrm{DN}$ values of the digital photo. Many previous studies confirmed that a stable linear relationship exists between DN and radiance for raw format image derived from digital cameras [5,11]. In addition, previous studies confirmed that the influence of dark current can be neglected during the imaging process, which indicates the derived offset value is close to zero [12]. Therefore, in the field experiment, we did not take a dark-bright target to calibrate the digital photo, and instead a reference panel was used to obtain the reflectance of the canopy and background. A stable linear relationship exists between the average $\mathrm{DN}$ value of the canopy color image and the reflected PAR based on the reference panel. The average values of the reference panel were used as the relative intensity values of PAR $R_{i}$, and the average values of the scene classes (all the exposed targets in the vertical scene image except for the reference panel) were used as the relative intensity values of $\mathrm{PAR}_{\mathrm{r}}$. Based on the linear relationship between $\mathrm{DN}$ and radiance of digital photo, the $\mathrm{PAR}_{\mathrm{i}}$ and $\mathrm{PAR}_{\mathrm{r}}$ in Equation (1) are approximated by photograph DN values as follows:

$$
\begin{gathered}
P A R_{i}=D N_{\text {ref }} / \rho_{\text {ref }} \\
P A R_{r}=D N_{\text {composite }}
\end{gathered}
$$

where $D N_{\text {ref }}$ is the average DN value of the red, green and blue (RGB) image for the reference panel, $\rho_{\text {ref }}$ is the reflectance of the reference panel, and $D N_{\text {composite }}$ is the average DN values which include all exposed components (including green vegetation, exposed and shadow soil, ground litter).

\subsection{Calculation of the Background-Absorbed Radiation and FPAR}

The background-absorbed radiation as defined in equation (1) includes two part, the absorbed PAR by the exposed background ( $\left.P A R_{\text {exposed background }}\right)$ and the green vegetation-covered background

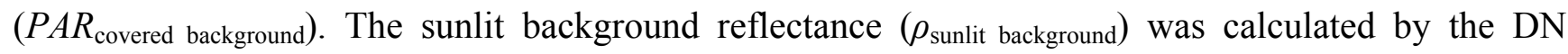



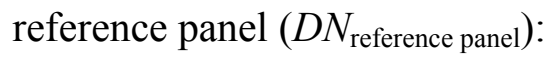

$$
\rho_{\text {sunlit background }}=\frac{\rho_{\text {ref }} * D N_{\text {sunlit background }}}{D N_{\text {reference panel }}}
$$

We took $\rho_{\text {sunlit background }}$ approximately as the exposed background (including exposed soil and ground litter) reflectance, and then $P A R_{\text {exposed background }}$ was calculated by $f_{c}$ and $\rho_{\text {sunlit background: }}$ 


$$
P A R_{\text {exposed background }}=D N_{\text {exposed background }} *\left(1-\rho_{\text {sunlit background }}\right) / \rho_{\text {sunlit background }} *\left(1-f_{c}\right)
$$

where $D N_{\text {exposed background }}$ is the average $\mathrm{DN}$ value for all the exposed soil (including sunlit and shaded soil) and ground litter pixels.

The green vegetation-covered background is hidden in the digital photo, and there is no way to detect its optical properties directly from the digital photo. In this paper, we assumed the same reflectance between the sunlit background and the green vegetation-covered background. A value of 0.05 was assumed for canopy transmittance $(\tau)$. Based on the above assumptions, the PAR component absorbed by green vegetation-covered $\left(P A R_{\text {covered background }}\right)$ can be calculated as,

$$
P A R_{\text {covered background }}=P A R_{i} * f_{c} * \tau *\left(1-\rho_{\text {sunlit background }}\right)
$$

Finally, the canopy FPAR was calculated according to Equation (2) as:

$$
F P A R=\left(P A R_{i}-P A R_{r}-\left(P A R_{\text {exposed background }}+P A R_{\text {covered background }}\right)\right) / P A R_{i}
$$

\section{Field Test Experiments}

In a fine day around noon with no cloud and wind, several field experiments were conducted in eight plots with four vegetation species (amur silvergrass, alfalfa, thyme, and e. japonicus) to validate the method at the Beijing precision agriculture demonstration base, which is located in the town of Xiao Tangshan, north of Beijing city $\left(40^{\circ} 11^{\prime} \mathrm{N}, 116^{\circ} 27^{\prime} \mathrm{E}\right)$, China. The plants in the experiment plots had a canopy height of approximately $30-50 \mathrm{~cm}$, and were suitable for FPAR measurement by both a digital camera and the SunScan canopy analysis system. We took two digital photos at nadir using the digital camera's raw file format for each plot. The reflectance of the reference panel in the exposed region was about 0.3. The SunScan instrument was used to measure the incident, reflected, and transmitted PAR in plant canopies. For each plot, we measured the reflected and transmitted PAR in four directions to reduce the heterogeneous distribution of plant canopy in the plot. Then, we calculated FPAR for each direction according to Equations (1) and (2), and also averaged the four FPAR values to validate the green vegetation FPAR derived from the digital photos.

Figure 3. Relation between FPAR derived from the digital camera and the SunScan instrument.

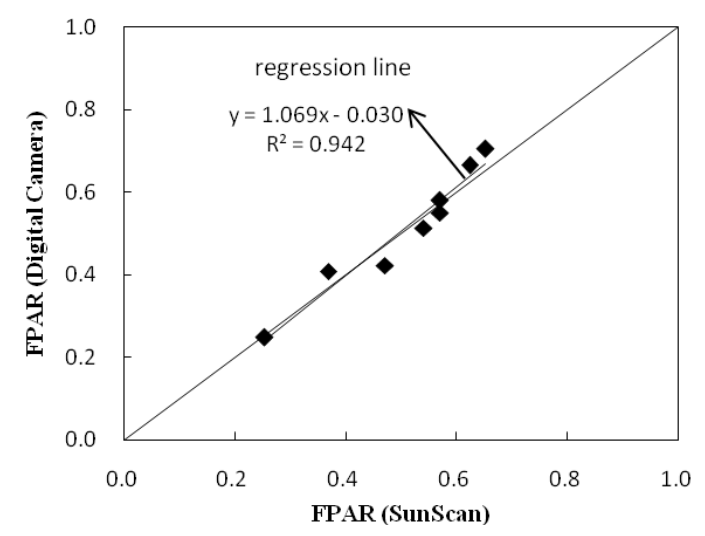


The comparison of FPAR measured by the digital camera and the SunScan instrument showed a significant correlation (Figure 3), with a coefficient of determination $\left(\mathrm{R}^{2}\right)$ of 0.942 (Figure 3), mean absolute error (MAE) of 0.031 and relative MAE of $6.037 \%$.

\section{Uncertainty of FPAR Measurement}

This novel green vegetation FPAR measurement method using a digital camera is rapid and simple, and the results validated well against measurements from the SunScan instrument. However, there are a few uncertainties as follows.

(1) FPAR is defined as the fraction of PAR absorbed by vegetation in the 400-700 nm spectrum, and the digital camera has adequate bandwidth covering the spectral range of 400-700 nm [5]. However, there are some gaps and overlapping regions of RGB. Therefore, some uncertainties exist in the FPAR calculated using the average of the DN values of RGB.

(2) The transmitted PAR on the green vegetation-covered background was assigned by empirical values, which should vary with canopy structure, such as LAI and illumination conditions (such as sun zenith angle and ratio of diffusion light). In this study, the canopy transmittance $(\tau)$ was assumed to be a constant 0.05 .

(3) According to Equations (1) and (2), the background absorbed PAR $\left(P A R_{g}\right)$ is one of the necessary parameters to calculate green vegetation FPAR [4]. For low vegetation, the covered background was not exposed, and its optical reflectance was unknown. In this study, the green vegetation covered background was assumed to have the same reflectance as exposed background, and this assumption might be one of the error sources of FPAR calculation by this developed method.

(4) An accurate classification of the digital camera image was a prerequisite for the accurate calculation of canopy. Classification errors would affect the results significantly. The biggest challenge was to distinguish the shadowed green leaves from shadowed background. In addition, the edges of the digital photograph have an off-nadir view, which would increase the estimated fractional cover of green vegetation $\left(f_{c}\right)$ around the edges of the photograph.

(5) Digital camera exposure settings and the reference panel reflectance are two potential sources of uncertainties. In order to produce a photograph pleasing to the eye, the gamma and white balance temperature are always used in digital cameras, which cause a non-linear relationship between DN and reflectance. Photos should be taken in a raw file format without the gamma and white balance. In addition, if the ground targets (including canopy and reference panel) are too bright or acquired by an auto-gain exposure setting, the image may be over-exposed or saturated (and therefore useless). Therefore, it is better to select a reference panel with a low reflectance, and also to use a digital camera's raw image file format.

(6) The edges of the digital photograph have an off-nadir view, which will increase the estimated factional cover of vegetation around the edges of the photograph. At a minimum, we need avoid setting the focal length of the lens to have a wide-angle field of view (FOV).

\section{Conclusion}

In this paper, we presented a novel ground-based green vegetation FPAR measurement method for low and potentially very-low canopy by integrating a digital camera and reference panel. Since the 
FPAR of such canopies defined in Figure 1 cannot be measured by the traditional radiometer (e.g., SunScan), there are no other independent ways to measure such very-low canopies, and then ultimately it is not possible to fully validate the method at this time. In this study, field-test canopies in eight plots with four low canopy species and a height of approximately $30-50 \mathrm{~cm}$, were selected, and they were suitable for FPAR measurement by both a digital camera and the SunScan canopy analysis system. Comparing the results showed that the new method was reliable and accurate, with a coefficient of determination $\left(\mathrm{R}^{2}\right)$ of 0.942 and a mean absolute error of 0.031 . Although there are still uncertainties in our method, especially regarding the fraction of absorbed PAR by green vegetation covered background and classification accuracy, theoretically, the method by digital camera has great potential to be effective in very-low canopies, based on the validation by field-test canopies. The new method provided an effective solution to measure green vegetation FPAR for low canopy vegetation using a digital camera and a reference panel. Compared to the traditional method such as SunScan method, this method is low cost and simple to operate.

\section{Acknowledgments}

The work in this article was funded by the National Basic Research Program of China (2010CB951701), and the National Natural Science Foundation of China (41201354 and 41222008).

\section{References}

1. Sellers, P.; Dickinson, R.; Randall, D.; Betts, A.; Hall, F.; Berry, J.; Collatz, G.; Denning, A.; Mooney, H.; Nobre, C. Modeling the exchanges of energy, water, and carbon between continents and the atmosphere. Science 1997, 275, 502.

2. McCallum, I.; Wagner, W.; Schmullius, C.; Shvidenko, A.; Obersteiner, M.; Fritz, S.; Nilsson, S. Comparison of four global fapar datasets over northern eurasia for the year 2000. Remote Sens. Environ. 2010, 114, 941-949.

3. Yang, W.; Tan, B.; Huang, D.; Rautiainen, M.; Shabanov, N.V.; Wang, Y.; Privette, J.L.; Huemmrich, K.F.; Fensholt, R.; Sandholt, I. Modis leaf area index products: From validation to algorithm improvement. IEEE Trans. Geosci. Remote Sens. 2006, 44, 1885-1898.

4. Jenkins, J.; Richardson, A.; Braswell, B.; Ollinger, S.; Hollinger, D.; Smith, M.L. Refining light-use efficiency calculations for a deciduous forest canopy using simultaneous tower-based carbon flux and radiometric measurements. Agr. Forest Meteorol. 2007, 143, 64-79.

5. Panditrao, A.M.; Rege, P.P. Estimation of spectral response of a consumer grade digital still camera and its application for temperature measurement. Indian J. Pure Appl. Phys. 2009, 47, 703-707.

6. Li, C.J.; Wang, J.H.; Liu, L.Y.; Wang, R.C. Automated digital image analyses for estimating percent ground cover of winter wheat based on object features. J. Zhejiang Univ. Agric. Life Sci. 2004, 6, 650-665.

7. De Jonckheere, J.F.; Brown, S.; Walochnik, J.; Aspöck, H.; Michel, R. Morphological investigation of three tetramitus spp. Which are phylogenetically very closely related: Tetramitus horticolus, tetramitus russelli n. Comb. And tetramitus pararusselli n. Sp. Eur. J. Protistol. 2005, 41, 139-150. 
8. De Kauwe, M.G.; Disney, M.I.; Quaife, T.; Lewis, P.; Williams, M. An assessment of the modis collection 5 leaf area index product for a region of mixed coniferous forest. Remote Sens. Environ. 2011, 115, 767-780.

9. Law, B.E. Estimation of leaf area index and light intercepted by shrubs from digital videography. Remote Sens. Environ. 1995, 51, 276-280.

10. Frazer, G.W.; Fournier, R.A.; Trofymow, J.; Hall, R.J. A comparison of digital and film fisheye photography for analysis of forest canopy structure and gap light transmission. Agr. Forest Meteorol. 2001, 109, 249-263.

11. Nieves, J.L.; Valero, E.M.; Hernández-Andrés, J.; Romero, J. Recovering fluorescent spectra with an rgb digital camera and color filters using different matrix factorizations. Appl. Opt. 2007, 46, $4144-4154$.

12. Dunlap, J.C.; Sostin, O.; Widenhorn, R.; Bodegom, E. Dark current behavior in DSLR cameras. Proc. SPIE 2009, doi:10.1117/12.806128.

(C) 2013 by the authors; licensee MDPI, Basel, Switzerland. This article is an open access article distributed under the terms and conditions of the Creative Commons Attribution license (http://creativecommons.org/licenses/by/3.0/). 